\title{
Cost Analysis of Construction and Demolition Waste Management : Case Study of the Pearl River Delta of China
}

\author{
Jingkuang Liu, ${ }^{1, *}$ and Yousong Wang ${ }^{2}$ \\ ${ }^{I}$ Department of Engineering Management, School of Business Administration, Guangzhou University, Guangzhou, \\ China; ${ }^{2}$ State Key Laboratory of Subtropical Architecture Science, South China University of Technology, Guangzhou, \\ China
}

\begin{abstract}
Currently, Construction and Demolition waste (C\&D waste) is a worldwide issue that concerns not only the construction management level of on-site managers but also the sustainable development of construction industry. In this paper, detailed formulas are listed for calculating the costs of three typical kinds of disposal routes of C\&D waste. They are Landfill Disposal, Recycling and Reuse. Using the specific formulas, the costs of new construction project in the Pearl River Delta Region of China are also estimated. The results of this study show: From 2010 to 2013, the Pearl River Delta region costs about 87.91 yuan (1US $\$=6.12$ yuan in September 2013) for landfill disposal of $1 \mathrm{t}($ tone) $\mathrm{C} \& \mathrm{D}$ waste, from the site collection management to landfill disposal; about 76.33 yuan for recycling of 1t C\&D waste, from the site collection management to the recycling treatment; 27.29 yuan for recycling and reusing of 1t C\&D waste, from the site collection management to recycling processing for reuse. On equal conditions, the recycling based reuse costs the lowest in C\&D waste management. Reasonable arrangement of C\&D waste treatment field. Additionally, in this paper, it is suggested that the government should make proper compensations to the contractors and professional processing businesses, to reduce their disposal cost and promote C\&D waste management. The results of this study can provide supportive data and theoretical basis for the $C \& D$ waste management decision-making in rapidly developing economies.
\end{abstract}

Keywords: C\&D waste, waste management, cost analysis, Pearl River Delta Region.

\section{INTRODUCTION}

As one of the major fixed asset formation sectors and cornerstone industries in the national economic system of China, the building sector is undergoing rapid development. Along with this, a lot of new construction and demolition and relocation projects produce huge quantities of $C \& D$ waste; thus, on one hand, natural resources are not used intensively, on the other hand, the waste pollutes the ecological environment. At present, $C \& D$ waste in China accounts for $30 \%-40 \%$ of total urban waste, and most of the C\&D wastes, are delivered, without undergoing treatment, to suburban or rural areas for disposal by means of open storage or landfill [1]. Thus C\&D waste not only incurs high transportation cost but occupies valuable land. In addition, the dust generated during transportation and transportation and in storage creates air pollution. According to relevant statistic data, construction projects in China produces 195 million tons of wasted and used materials a year, and daily discharge of urban C\&D waste amounts to 27,000 tons in just a few rapidly developing cities like Beijing, Shanghai, Guangzhou, Shenzhen and Tianjin [2]. Unfortunately, China still adopts conventional landfill or open storage on refuse sites for waste disposal at present, and has not attached enough importance to C\&D waste generation and disposal [3]. Government regulation is inefficient and its function has not been fully executed, few building developers and contractors

*Address correspondence to this author at the Department of Engineering Management, School of Business Administration, Guangzhou University, Guangzhou, China; Tel: +8613450289815; Fax: (+86)020-39366799;

E-mail: ljkgowell@163.com have developed C\&D waste management plan. They have placed more emphasis on pursuing the maximization of their own economic interests than on controlling the generation of C\&D waste. Illegal dumping and landfill not only have high cost but have also brought serious pollution to the environment [4].

We selected to study the implementation of C\&D waste management in the Pearl River Delta, because the Pearl River Delta Region lies at the lower reaches of the Pearl River of the south-eastern part of Guangdong Province and is adjacent to Hong Kong and Macau and its own developed economy and has large scale construction activities from which a great amount of $C \& D$ waste is produced, posing tremendous negative impact on the environment.

To better analyze the cost of C\&D waste management, the implementation of $C \& D$ waste management in the Pearl River Delta of China that is developed in construction industry was selected as an example to conduct cost analysis on C\&D waste management ways (Landfill Disposal, Recycling and Reuse), and specific formulas were given for cost calculation. Finally, based on these investigation and analyses, conclusions are arrived and suggestions given. The results of this study can provide supportive data and theoretical basis for the $C \& D$ waste management decision-making in rapidly developing economies, such as China, India and Brazil.

\section{REVIEWS}

C\&D waste management costs differ due to the difference in regions and economic development. Scholars at 
home and abroad have made researches on $\mathrm{C} \& \mathrm{D}$ waste management costs, for example,

Begum (2006) conducted cost-benefit analysis of on-site $\mathrm{C} \& \mathrm{D}$ waste recycling and reusing in Malaysia, by the statistical method, he held that the total revenue of on-site C\&D waste recycling and reusing is composed of the saved purchasing cost, saved collection and transportation cost, saved landfilling cost, sales income and other intangible benefits; and the total cost of is mainly composed of the collection and separation cost, equipment purchasing cost, storage cost and other intangible costs [5].

Xaver Duran et al. (2006) simulated the economical efficiency and reliability of demolition waste recycling in Ireland, confirmed that the recycling centers are profitable under certain conditions, and put forward some feasible policies aimed in view of these conditions [6].

Tam (2008) conducted contrastive cost-benefit analysis on the current disposal way and the concrete recycling in Australia, by using accounting and statistical ways, and found that the concrete recycling is more effective than the current disposal way [7].

$\mathrm{Hu}$ et al. (2011) introduced the four methods of C\&D waste management in current China (illegal dumping, simple landfill, comprehensive disposal and on-site recycling), and took Chongqing as an example to calculate the lowest cost of on-site recycling (40.11 yuan/t) by using the full cost accounting method, showing that this method is the direction of future development. The two scholars mentioned above analyzed the $C \& D$ waste management costs of our country from different aspects [8].

The scholars mentioned above analyzed C\&D waste management costs of our country from different aspects. In addition, due to the factors that affect the cost of C\&D waste management are dynamic and interactive, the system dynamics is applied to the research of cost-benefit modeling of C\&D waste management. Many scholars have studied this area, for example:

W. Zhao et al. (2011), modeled and compared the various demolition waste recycling centers in Chongqing based on the method of system dynamics, analyzed the cost benefit of different combinations, concluded three main factors influencing the cost benefit and put forward some improvement suggestions [9].

Yuan et al. (2012) built a system dynamics modeling of the demolition waste processing chain in Shenzhen, analyzed the sensitivity of each parameter in the system, concluded the cost-benefit curve of the disposal center and put forward the measures to improve the key affecting factors [10].

Wang et al. (2012), taking a housing project in Shenzhen city as an example, built a system dynamics model for economic evaluation of C\&D waste with Vensim, and simulated the interrelations among the internal material cost, transportation cost, landfill costs, sorting and classification cost in economic evaluation of $C \& D$ waste. The simulation results show that the material and the transport costs account for $99.89 \%$ of the total disposal cost; landfill, sorting and classification only about $0.1 \%$; contractors, developers, professional processing businesses and other participants of the building have not taken the minimization and recycling of C\&D waste as their focus, mainly because of the low cost of landfill [11].

André Coelho, Jorge de Brito (2013,a,b) research revealed that investment in a large-scale high-level $C \& D$ waste recycling facility is a multi-million euro enterprise, but has a high profit potential, even in the absence of specific regulatory measures which could help C\&D waste material. In addition, for a 350 tonne/h facility, average gate fees of $€ 48 /$ tonne for mixed and $€ 8 /$ tonne for separated input materials, the need to spend around 1.13 million euros a year on rejected material transportation and another 10.3 million euros a year to dump it in landfills (or onward transport for further treatment), a 2-year return on investment period is possible $[12,13]$.

To sum up, analysis of C\&D waste management cost is an issue that concerns worldwide researchers. Although the costs vary in different economies and even different parts of the same country, composition of the cost is roughly the same. Through research and analysis of C\&D waste management costs, government of countries and regions can better develop policies for effective C\&D waste management.

\section{COST GENERATION IN ON-SITE C\&D WASTE MANAGEMENT}

A typical waste management process in a construction project is comprised of the following main activities [14-16]:

1. Collection of waste materials,

2. Transport of materials to the storage area located on-site,

3. Sorting of materials to different waste types, and

4. Storage in waste material bins until off-site transport begins.

The sorting of materials to different material bins is required only for the materials types for which the strategies are reuse and/or recycling. All of the other activities are also necessary for the waste management alternative of landfill disposal. Therefore, when evaluating the costs and benefits of reuse and recycling, an additional cost component must be incorporated.

From Fig. (1), it can be seen that in the overall construction process, resources, materials, manpower and equipment are first invested, and then $C \& D$ waste is produced with time and cost accumulation. Collecting and sorting waste takes time and requires cost. The storage site is required if the waste is collected but not handled in time, therefore cost is generated. Finally, with the transportation of C\&D waste to a disposal field or comprehensive treatment place, more cost is generated. Therefore, the total cost of on-site management of C\&D waste can be expressed by the following formula: The cost component of $\mathrm{C} \& \mathrm{D}$ waste from the activities modeled under Fig. (1), is comprised of four components as shown below:

$C_{M}=C_{C \& T}+C_{\text {sort }}+C_{\text {store }}$

where,

$C_{C \& T}=$ cost of collection and on-site transport of waste material 


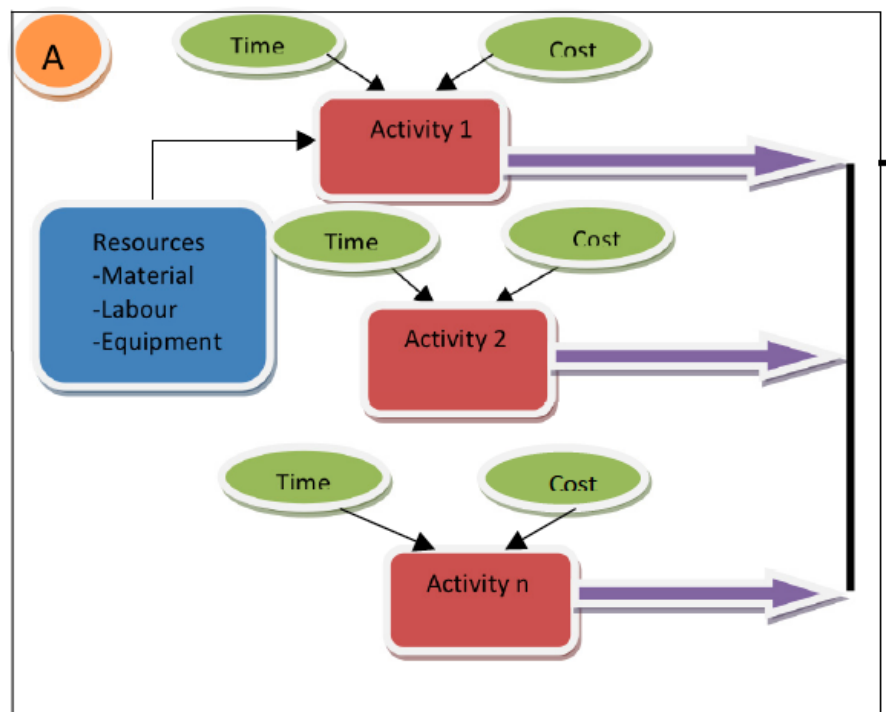

Where:

A-Waste generation process

B-Collection on-site transportation of waste materials \& sorting process

C-Material store process

D-Off-site transportation of materials for processing or for disposal

Fig. (1). On-Site Waste Management Process.

$C_{\text {sort }}=$ cost of sorting waste materials on-site

$C_{\text {store }}=$ cost of storing waste materials on-site

The cost of material storage is based on the number of waste material bins required for a waste type, because waste material bins typically incur an additional cost, as they are rented to the construction companies by the waste hauling company. Therefore, the cost calculation for drywall waste material type is:

$C_{\text {store }}=N \times R_{d} \times D$

where, $N$ number of waste material bins required on-site, $R_{d}$ daily rate of rental (yuan/bin/day), $D$ activity duration (days).

\section{IDENTIFICATION OF THE FULL-COST FACTORS OF C\&D WASTE MANAGEMENT}

\subsection{Cost of Landfill Disposal}

The landfill disposal process of a waste material can be identified as comprising of the following three consecutive stages at which costs are incurred:

a) Collection, transportation, and storage of waste on-site,

b) Off-site transportation of waste to landfill, and

c) Weighing and admission of waste into landfill.

The total landfill disposal cost (for drywall, as an example) can, therefore, be calculated as follows:

$C_{L F}=C_{M}-C_{\text {sort }}+C_{T L F}+C_{\text {Disposal }}$

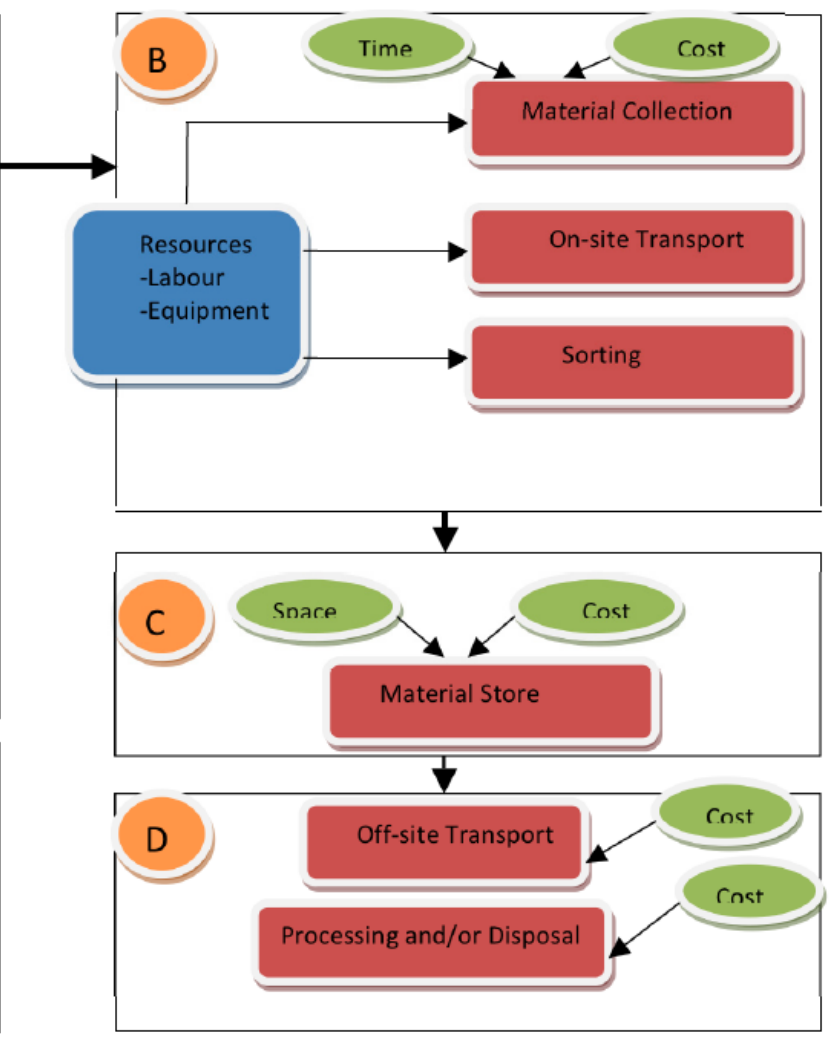

where, $C_{M}=$ Total cost of processing drywall waste Module 2, This is calculated from Equation (1)

$C_{\text {sort }}=$ Cost of sorting materials (already accounted for in Module 2)

$C_{T L F}=$ Transport cost of materials to nearest landfill

$C_{\text {Disposal }}=$ Cost of material weighing, admission and disposal at landfill

$C_{T L F}=Q \times R_{T L F} \times$ Dist $_{L F}+L_{\text {Rate }} \times N \times n_{\text {Lifts }}$

$C_{\text {Disposal }}=Q \times R_{\text {Disposal }}$

where, $Q=$ quantity of drywall waste $(\mathrm{kg})$

$R_{T L F}=$ Rate of transport cost to landfill (yuan $/ \mathrm{km} / \mathrm{kg}$ )

Dist $_{L F}=$ Distance to the nearest landfill $(\mathrm{km})$

$R_{\text {Disposal }}=$ Rate of landfill disposal cost (yuan $/ \mathrm{kg}$ )

$L_{\text {Rate }}=$ Lift rate (yuan/lift)

$n_{\text {Liffs }}=$ Number of lifts

\subsection{Costs of Recycling Waste Materials}

The recycling process can be identified to comprise of the following four consecutive stages at which costs are incurred:

a) Collection, transportation and storage of waste on-site,

b) Sorting into different categories of waste,

c) Transporting sorted waste to an off-site recycling facility, and 
d) Weighing and admission of waste into the recycling facility.

The total recycling cost (benefit) (for drywall, as an example) can, therefore, be calculated as follows:

$C_{R C}=C_{M}+C_{T R C}+C_{A D M}$

where, $C_{M}=$ the total cost of processing drywall waste (Module 2), which is calculated from Equation (1)

$C_{T R C}=$ Transport cost of materials to nearest recycling facility

$C_{A D M}=$ Cost (benefit) of material admission to recycling facility

$C_{T R C}, C_{A D M}$ is calculated as follows:

$C_{T R C}=Q \times R C F \times R_{T R C} \times$ Dist $_{R C}+L_{\text {Rate }} \times N \times n_{\text {Lifts }}$

$C_{A D M}=Q \times R C F \times R_{A D M}$

where, $Q=$ Quantity of drywall waste (tonnes)

$R C F=$ Recyclable Fraction of the total waste generation

$R_{\text {TRC }}=$ Rate of transport cost to recycling facility (yuan $/ \mathrm{km} /$ tonne)

Dist $_{R C}=$ Distance to the nearest recycling facility $(\mathrm{km})$

$R_{A D M}=$ Rate of admission cost to the recycling facility (yuan/tonne)

\subsection{Costs of Reuse}

Reuse of waste materials, which may be a better solution to waste materials generated from demolition projects. However, for the completeness of the model, reuse costs and benefits were also included in the simulation model. The reuse process can be identified as comprised of the following costs:

a) Collection, transportation and storage of waste on-site,

b) Sorting into different categories of waste,

c) Transporting sorted waste to an off-site or on-site location for further processing if required, and

d) Processing materials for reuse (reapplication).

The total reuse cost (benefit) (for drywall as an example) can, therefore, be calculated as follows:

$C_{R U}=C_{M}+C_{T R U}+C_{\text {Process }}-B_{R U}$

where, $C_{M}=$ Total cost of processing drywall waste (Module 2), which is calculated from Equation (1)

$C_{T R U}=$ Transport cost of materials to off-site or on-site processing centre

$C_{\text {Process }}=$ Cost of processing material

$B_{R U}=$ Benefit of reuse

$C_{T R U}, C_{\text {Process }}$ is calculated as follows:

$C_{\text {TRU }}=Q \times R U F \times R_{\text {TRC }} \times$ Dist $_{R U}$

$C_{\text {Process }}=Q \times R U F \times R_{\text {Process }}$ where, $Q=$ Quantity of drywall waste (tonnes)

$R U F=$ Reusable fraction of the total waste generation

$R_{T R U}=$ Rate of transport cost to reuse processing facility (yuan $/ \mathrm{km} /$ tonne)

Dist $_{R U}=$ Distance to the reuse processing facility $(\mathrm{km})$

$R_{\text {Process }}=$ Rate of process cost for reusing (yuan/tonne)

\section{QUANTIFICATION AND CALCULATION OF PARAMETERS OF C\&D WASTE MANAGEMENT COSTS}

In this paper, as is calculated by the unit cost of disposing 1t C\&D waste in the Pearl River Delta region, quantification of the main parameters of $\mathrm{C} \& \mathrm{D}$ waste management costs and the relevant basis are shown as follows:

(1) Calculation of the total cost of landfill disposal

$$
\begin{aligned}
& C_{L F}=C_{C \& T}+C_{\text {store }}+Q \times R_{T L F} \times \text { Dist }_{L F}+ \\
& L_{\text {Rate }} \times N \times n_{\text {Lifss }}+Q \times R_{\text {Disposal }} \\
& =50+20+0+1 \times 28 \% \times 1.13 \times 25+0+1 \times 10 \\
& =87.91 \text { yuan } / t
\end{aligned}
$$

(2) Calculation of the total cost of recycling

$$
\begin{aligned}
& C_{R C}=C_{C \& T}+C_{\text {sort }}+C_{\text {store }}+Q \times R C F \times R_{T R C} \times \\
& \text { Dist }_{R C}+L_{\text {Rate }} \times N \times n_{\text {Liffs }}+Q \times R C F \times R_{A D M} \\
& =50+20+0+1 \times 28 \% \times 1.13 \times 20+0+1 \times 28 \% \times 0 \\
& =76.33 \text { yuan } / t
\end{aligned}
$$

(3) Calculation of the total cost of reuse

$$
\begin{aligned}
& C_{R U}=C_{C \& T}+C_{\text {sort }}+C_{\text {store }}+Q \times R U F \times R_{T R C} \times \\
& \text { Dist }_{R U}+Q \times R U F \times R_{\text {Process }}-B_{R U} \\
& =50+20+0+1 \times 28 \% \times 1.13 \times 20+1 \times 28 \% \times 21.3-65 \\
& =27.29 \text { yuan } / t
\end{aligned}
$$

Substitute the quantitative data of parameters collected in Table 1 into the formula (12)- (14), three typical C\&D waste management costs are obtained.

According to the calculated result shown in Fig. (2), in the Pearl River Delta Region, it costs about 87.91 yuan for landfill disposal of $1 \mathrm{t} \mathrm{C} \& \mathrm{D}$ waste, from the site collection management to landfill disposal; about 76.33 yuan for recycling of 1t C\&D waste, from the site collection management to the recycling treatment; 27.29 yuan for recycling and reusing of $1 \mathrm{t} C \& D$ waste, from the site collection management to recycling processing for reuse. Therefore, it can be seen that on equal conditions, the recycling based reuse costs the lowest in C\&D waste management. In order to validate the calculated result, investigation was made on the landfill disposal in the Pearl River Delta Region in 2012. The market price was 80 to 100 yuan for disposal of $1 \mathrm{t} C \& D$ waste, showing that the calculated result was consistent with the actual situation. In addition, as the illegal landfill is involved in the disposal ways, viz. when the transportation distance Dist $_{L F}$ between the site and the landfill field is $5 \mathrm{~km}$, it can be regarded as illegal landfill, which lowers the management 
Table 1. Quantification of the Main Parameters and the Corresponding Basis

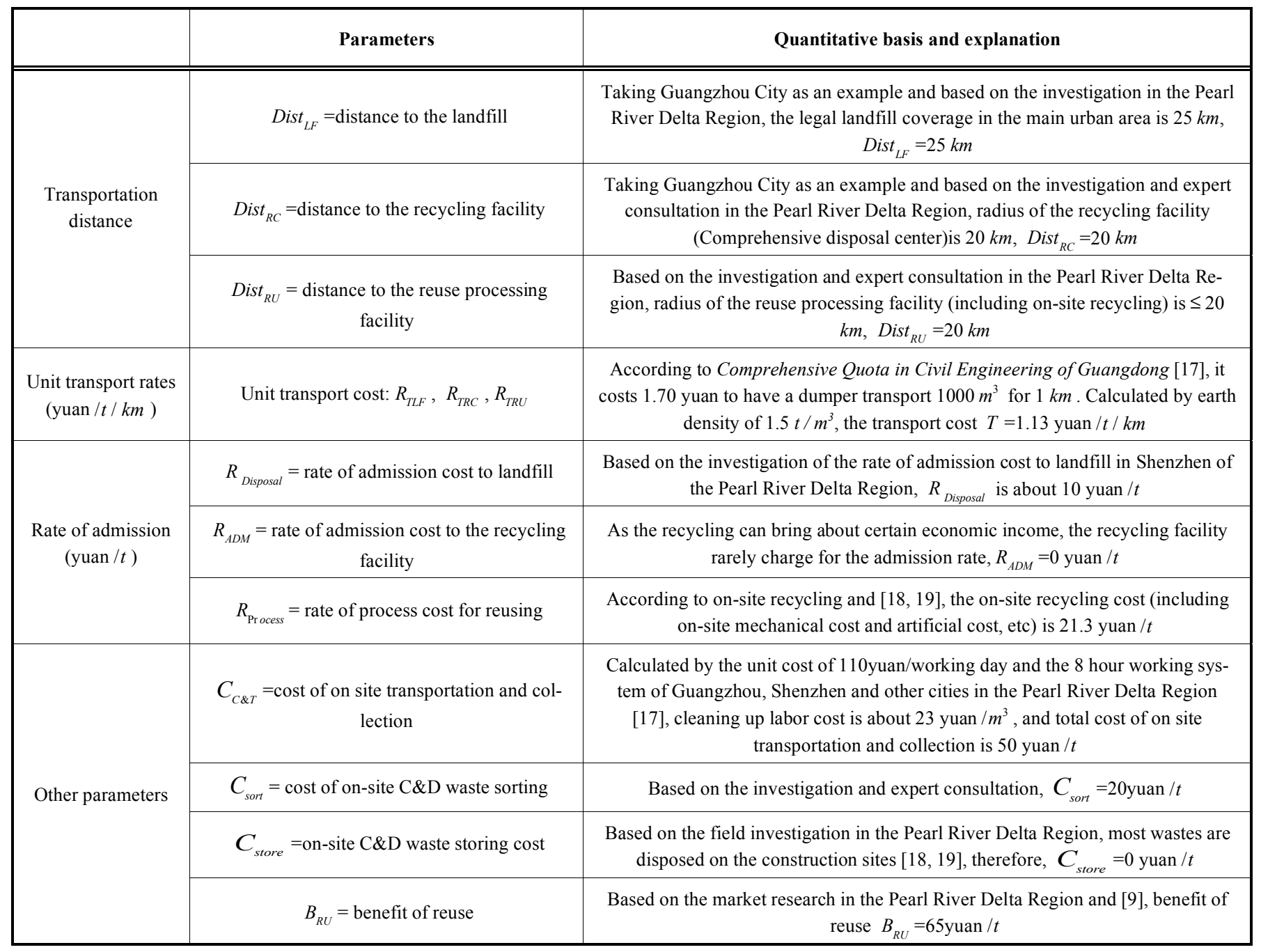

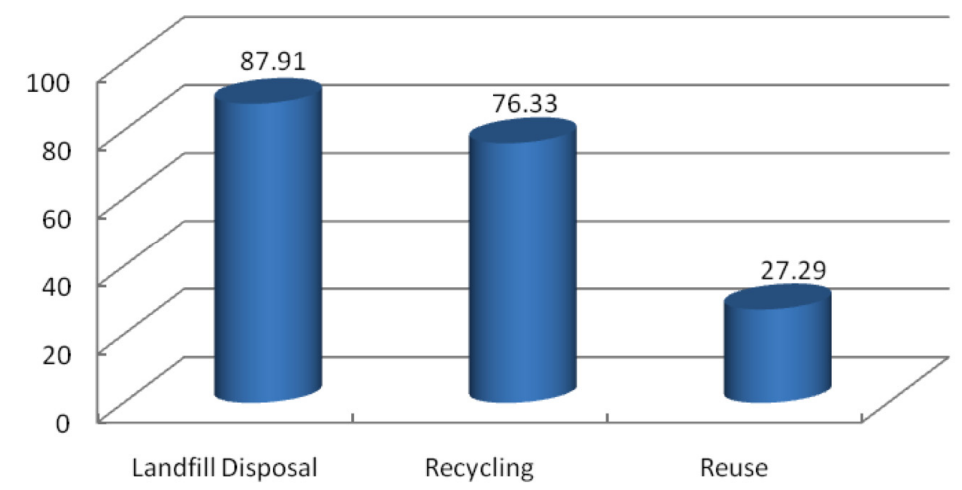

Fig. (2). Calculation of C\&D waste management cost in the Pearl River Delta Region (Unit: yuan/t; from 2010 to 2013 ).

cost but causes environment pollution, brings more management cost to the society, and raises the total cost of landfill disposal.

Recycling is included in the processing for reuse of the C\&D waste, viz. when the distance $D_{i s t}$ from the site to the reuse processing facility is zero, the total recycling cost is 10.96 yuan/t. When the benefit of reuse $B_{R U}$ increases, the total recycling cost will be negative, and thus the on-site recycling will get a certain surplus profit.

\section{CONCLUSION AND RECOMMENDATIONS}

In this paper, three typical C\&D waste disposal methods used in the Pearl River Delta Region are introduced. According to the investigation and calculation results, in the current period (2010-2013), it costs about 87.91 yuan for landfill disposal of $1 \mathrm{t}$ C\&D waste, from the site collection management to landfill disposal; about 76.33 yuan for recycling of 1t C\&D waste, from the site collection management to the recycling treatment; 27.29 yuan for recycling and reusing of 
1t C\&D waste, from the site collection management to recycling processing for reuse. It is concluded that on equal conditions, the recycling based reuse costs the lowest in C\&D waste management. The calculation is roughly in accordance with $\mathrm{Hu}$ et al. (2011) findings of the C\&D waste disposal costs in Chongqing [8].

To achieve economic feasibility of C\&D waste minimization in the Pearl River Delta Region and maximum of ratio of savings to costs, it could be recommended:

(1) Reasonable arrangement of the $C \& D$ waste disposal field, which refers to the recycling treatment site or comprehensive disposal site. Take Guangzhou city for an example, according to estimation the Guangzhou sanitation department, the new construction area in Guangzhou will increase at a speed of 10 million square meters per year, and the reformation of buildings in the old urban area will grow at a speed of 5 million square meters per year. 20 million tons of C\&D waste are generated within one year, And the with the accumulated $C \& D$ waste for nearly 20 years, total up to 60 million tons, so Guangzhou needs 6000 acres of landfills to deal with the waste every year [20]. However, investigation shows that, most of the C\&D waste is delivered to Huadu District of Guangzhou Nanhai District of Foshan, Zhongtang District of Dongguan. By doing this, the long haul distance increases the operational costs, and those remote areas are not easy to control and manage, resulting in new environmental pollution. Due to geographical constraints and other factors, except Tianhe District, Haizhu District Yuexiu District and Liwan District where C\&D waste disposal sites can not be built, we suggest that Guangzhou municipal government build more than 5 million cubic meters of temporary C\&D waste disposal sites in Baiyun District, Huanpu District, Panyu District, Nansha District, Luogang District and other relatively near regions, and gradually achieve the resource goal of $C \& D$ waste. The construction and comprehensive utilization of C\&D waste will be incorporated into the plan for the development of recycling economy

(2) Advocate Reuse of $\mathbf{C} \& D$ waste. The cost accounting shows that the direct costs and external costs of Reuse are the lowest, so On-site recycling should guide the making of C\&D waste management policy. However, the investigation shows that there are almost no sites in Guangzhou and even the whole economically-developed Pearl River Delta Region using the jaw crusher or other measures to strengthen on-site recycling [19]. This is mainly because the contractors have adopted cheap disposal routes, such as illegal dumping or nearby controlled dumping. With the increasingly strictness of the legal supervision and the execution of the plan of centralized recycling, the disposal costs of the C\&D waste will inevitably rise [21]. In the foreseeable future, in order to reduce the costs of transport and centralized recycling, the party responsible for $\mathrm{C} \& \mathrm{D}$ waste will have to take the measures to strengthen on-site recycling. Therefore, to vigorously promote the on-site recycling is both the recycling enterprise's business opportunity and in accordance with the government's goal to save the overall costs of the C\&D waste management. It should become the future development trend of the $\mathrm{C} \& \mathrm{D}$ waste management.
(3) Adopting the compensation incentive measures for C\&D waste management. It is suggested that the government should make proper compensations to the contractors and professional processing businesses, help them to reduce the disposal cost, and therefore promote C\&D waste management. The contractors and professional processing businesses will be less positive if they are required to send the $C \& D$ waste to the landfill or recycle treatment field, considering to the high costs, they may tend to use illegal dumping. In the current period, the $\mathrm{C} \& \mathrm{D}$ waste recycling ratio is low, and the market was not formed, it is suggested that the government can take appropriate cost compensation incentive measures to completely eradicate illegal dumping.

\section{CONFLICT OF INTEREST}

The author(s) confirm that this article content has no conflicts of interest.

\section{ACKNOWLEDGEMENT}

The author would like to acknowledge the valuable suggestions of the editor and two anonymous reviewers.

\section{REFERENCES}

[1] L.C. Wang, and Y.C. Zhao, "C\&D waste disposal and recycling." China Chemical Industry Press, Beijing, pp. 7, 2004 (in Chinese).

[2] P. Li, "Comprehensively utilize construction waste and vigorously develop economic cycle", Practice and Theory of Sezs, vol. 06, pp. 84-91, 2007. (in Chinese).

[3] J.K. Liu, and Y.S. Wang, "Establishment and application of performance assessment model of waste management in architectural engineering projects in China", Journal of Systems Engineering Procedia, vol. 4, pp. 147-155, 2011.

[4] Y.S.Wang, J.W. Zhou, and Y. Zhan, "Investigation and analysis on minimization and reclamation of construction waste in Ghuangzhou", China Engineering Management Forum, Changsha, vol.2, pp. 470-476, 2011. (in Chinese).

[5] R. Begum, C. Siwar, J.J. Pereira, and A.H. Jaafar, "A benefit-cost analysis on the economic feasibility of construction waste minimization: the case of Malaysia", Resources, Conservation \& Recycling, vol. 48, no.1, pp. 86-98, 2006.

[6] X. Duran, H. Lenihan, and B. O'Regan,"A model for assessing the economic viability of construction and demolition waste recycling - the case of Ireland", Resources, Conservation and Recycling, vol. 46, no. 3, pp. 302-320, 2006.

[7] V.W.Y. Tam, "Economic comparison of concrete recycling: A case study approach", Resources, Conservation and Recycling, vol. 52, no. 5, pp. 821-828, 2008.

[8] M.M. Hu, Q. He, S.Y. Shi, and D.D. Qi, "Cost Analysis of Construction and Demolition Waste Management: Case of Chongqing", Journal of Building Economy, vol. 4, pp. 93-97, 2011. (in Chinese).

[9] W. Zhao, H. Ren, and V.S. Rotter, "A system dynamics model for evaluating the alternative of type in construction and demolition waste recycling center - The case of Chongqing, China", Resources, Conservation and Recycling, vol. 55, pp. 933-944, 2011.

[10] H.P. Yuan, A.R. Chini, and Y.J. Lu, "A dynamic model for assessing the effects of management strategies on the reduction of construction and demolition waste", Waste Management, vol. 32, pp. 521-531, 2012.

[11] J.Y. Wang, Z.D. Li, and X.F. Wang, "Economic cost estimation of C\&D waste based on system dynamics", Journal of Building Economy, vol. 8, pp. 95-98, 2012. (in Chinese).

[12] A. Coelho, and J. de Brito. "Economic viability analysis of a construction and demolition waste recycling plant in Portugal-part I: location, materials, technology and economic analysis", Journal of Cleaner Production, vol. 39, pp. 338-352, 2013.

[13] A. Coelho, and J. de Brito, "Economic viability analysis of a construction and demolition waste recycling plant in Portugal - Part II: 
Economic sensitivity analysis", Journal of Cleaner Production, vol. 39, pp. 329-337, 2013.

[14] B.A.D.S. Wimalasena, "A planning tool for construction waste management", University of Calgary, Ph.D. Thesis, Calgary, 2011.

[15] B.A.D.S. Wimalasena, J.Y. Ruwanpura, and J.P.A. Hettiaratchi, "Modeling construction waste generation towards sustainability", Proceedings of the 2010 Construction Research Congress (CRC), Banff, Alberta, Canada, pp. 1498-1507, 2010 (b).

[16] J. Stenis, "Construction waste management based on industrial management models: A Swedish case study", Waste Management and Research, vol. 23, no. 1, pp.13-19, 2005.

[17] The office of Guangdong Province Construction Cost Management (OGPCCM). Comprehensive quota of Guangdong Province architectural engineering and fitting decoration project. China Plan Publishing Company, Beijing, 2010. (in Chinese).
[18] J.K. Liu, Y.S. Wang, and Y.Y. Lin, “A model for quantification of construction waste in new residential buildings in pearl river delta of China", The Open Construction and Building Technology Journal, vol. 6, pp.398-403, 2012.

[19] J.K. Liu, "Research on Cost Compensation Model for Construction and Demolition Waste Management", South China University of Technology, Ph.D. Thesis, Ghuangzhou, 2013 [in Chinese]

[20] J.W. Zhou, "Survey Analysis and Countermeasures of C凶D Waste Problem in South China", South China University of Technology, Master Thesis, Ghuangzhou, 2011 [in Chinese].

[21] S.R. Parthan, M.W. Milke, D.C. Wilson, and J.H. Cocks, “ Cost estimation for solid waste management in industrializing regions Precedents, problems and prospects", Waste Management, vol. 32, pp. 584-594, 2012.

Received: November 15, 2013

Revised: December 18, 2013

Accepted: December 18, 2013

(C) Liu and Wang; Licensee Bentham Open.

This is an open access article licensed under the terms of the Creative Commons Attribution Non-Commercial License (http://creativecommons.org/licenses/by-nc/3.0/) which permits unrestricted, non-commercial use, distribution and reproduction in any medium, provided the work is properly cited. 